\title{
MAKNA TEKS DRAMA TARI LANGEN CARITA JAKA TINGKIR
}

\author{
Nanda Isa Fajarina \\ Institut Seni Indonesia (ISI) Surakarta \\ Jalan Ki Hadjar Dewantara No. 19 Kentingan, Jebres, Surakarta 57126 \\ Sutarno Haryono \\ Institut Seni Indonesia (ISI) Surakarta
}

\begin{abstract}
Abstrak
Penelitian DramaTari Langen Carita Jaka Tingkir bertujuan untuk mendiskripsikan makna Teks dan bentuk Drama Tari Langen Carita Jaka Tingkir. Penelitian inimenggunakan Konsep Pragmatik menurut Maryono dan konsep seni pertunjukan menurut maryono. Penulisan skripsi ini menggunakan metode penelitian kualitatif dimanadi dalam metodeini bertujuan untuk memperoleh data sebanyak-banyaknya kemudian dianalisis dan dideskripsikan secara mendalam, sehingga dapat memberikan gambaran dan pemaparan mengenai Mana Teks Drama Tari Langen Carita Jaka Tingkir. Tehnik pengumpulan data yang digunakan adalah observasi, wawancara dan studi pustaka. Hasil penelitian menunjukan bahwa Drama Tari langen Carita Jaka tingkir memiliki sebuah mana teks karena didalamnya memiliki sebuah cerita yang mengandung makna nilai-nilai kehidupan. Nilainilai kehidupan tersebut diwujudkan dalam bentuk gerak, ekspresi, tembang dan juga dialog.nilai-nilai tersebut mampu diwujudkan dengan rasa melaui bentuk sajian Drama Tari langen Carita Jaka Tingkir. Drama Tari Langen Carita Jaka Tingir mampu mengungapkan sebuah rasa kegembiraan seorang anak yang sedang bermain dan menggelar langen Cerita dismping itu anak-anak tersebut mampu memberikan rasa gagah, berani dan berwibawa. Rasa tersebut dituang dalam sebuah tokoh Jaka tingkir, buaya dan juga prajurit. Dengan adanya sebuah makna teks Drama Tari Langen Carita Jaka tingkir diharapkan mampu memberikan sebuah pengajaran kepadapara generasi muda untuk lebih mencintai kebudayaan local atau cerita pahlawan local yang sekarang ini posisinya mulai tergantikan oleh perkembangan jaman.
\end{abstract}

Kata kunci: Drama tari langen Carita Jaka Tingkir, Makna teks, bentuk.

\section{Abstract}

Research DramaTari LangeJaka Tingkir aims to describe the meaning of the text and the form of dance Drama Langen Carita Jaka Tingkir. This research uses the Pragmatic Concept according to Maryono and the concept of performing arts according to maryono. Writing this thesis using qualitative research methods where in this method aims to obtain data as much as possible then analyzed and described in depth, so as to provide description and exposure of Mana Text Drama Dance Langen Carita Jaka Tingkir. Data collection techniques used are observation, interview and literaturestudy. The result of the research shows that the Dance Drama of Carita Jaka Tingkir has a text where because it has a story that contains the meaning of life values. Values of life is manifested in the form of motion, expression, song and also dialog. These values can be realized with a taste through the form of dish Dance Drama Dance Carita Jaka Tingkir. The Langen Carita Jaka Tingir Dance Drama is able to express a sense of joy of a child who is playing and deploying. The story of dismping children is able to give a sense of dashing, courage and dignity. The taste is poured in a character Jaka tingkir, crocodile and also the soldier. With the 
existence of a text meaning of Dance Drama Langen Carita Jaka tingkir is expected to give a teaching to the young generation to better love local culture or local hero story which is now its position began to be replaced by the development of the era.Top of Form

Keywords: Drama Tari Langen Carita Jaka Tingkir, the meaning of text, form.

\section{PENDAHULUAN}

Langen Carito Joko Tingkir merupakan sebuah bentuk Drama Tari Jawa yang muncul pada tahun 2017 yang diciptakan oleh tiga Dosen Institut Seni Indonesia Surakarta yaitu Slamet, RM. Pramutomo dan Tubagus Mulyadi. Dikatakan Drama Tari karena didalamnya memiliki bentuk sajian berupa gerak tari yang dikolaborasikan dengan alur cerita dan dialog antar pemain. Menurut soedarsono, Jaka Sukiman dan Retna Astuti "drama memiliki arti dalam bahasa yunani Dramoi yang berarti berbuat, berlaku, bertindak, bereaksi dan sebagainya" (soedarsono, Jaka Sukiman, Retna 1984:66). Tari didefinisikan oleh Soedarsono "ungkapan perasaan manusia tentang sesuatu dengan gerak gerak ritmis yang indah" (Soedarsono, 1996:6). Sama Halnya dengan Drama tari langen Carita Jaka Tingkir yang memiliki aspek gerak ritmis, berbuat, bertindak dengan gerak tari, alur cerita dan musik hingga membentuk suatu drama tari. Drama Tari langen Carita Jaka Tingkir menggabungkan gerak tari, musik gamelan, antawecana, dialog, narasi, dan juga tembang dalam setiap struktur sajiannya. Langen Carita Jaka Tingkir dipentaskan dalam sebuah acara nemlikuran yang berada di SMK 8 Surakarta pada tanggal 26 juli 2017.

Lahirnya Drama Tari langen Carita Jaka Tingkir berpijak dari Langendriya dan Langen Mandrawanara yang ada di Mangkunegran Surakarta. Pada awalnya Langendriya lahir di Yogyakarta oleh Raden
Tumenggung Purwa Diningrat dan Pangeran Mangkubumi pada tahun 1876. Kemudian oleh R. M. H. Tandhakusuma (Menantu K. G. P. H Mangkunegaran IV) Langendriya diubah menjadi gaya Surakarta pada tahun 1881. Menurut versi Kasunanan Surakarta yang mengilhami bentuk drama tari ini ialah tradisi ura-ura atau menembang yang dilakukan buruh batik dan diprakarsai oleh Godlieb ; seorang pengusaha batik, di surakarta dengan lakon yang diperankan adalah cerita Damar Wulan.

Drama Tari kedua yang mengilhami penciptaan Langen Carito Joko tingkir ialah Langen Mandrawanara. langen Mandrawanara juga merupakan suatu bentuk Opera Jawa dengan para penarinya melakukan joget jengkeng. Langen Mandrawanara lahir atas buah karya K. P. H Yudonegoro III menggunakan konsep dan pola Langendriya namun lakon yang diperankan berbeda dengan Langendriya. Langen Mandrawanara menggunakan cerita Ramayana dalam bentuk pertunjukannya. Langendriya dan Langen Mandrawanara erat sekali kaitannya dalam penggarapan Langen Carita Jaka Tingkir, dikarenakan langen Carita Jaka Tingkir adalah bentuk perkembangan dari Langendriya dan Langen Mandrawanara. Bentuk perkembangan ini merupakan suatu hal yang sangat menarik untuk dikaji karena di dalam struktur sajian langen Caritan Jaka Tingkir memuat sebuah cerita dan ide garap yang berbeda dan menarik dari sebelumnya. Lahirnya Drama Tari langen Carita Jaka 
Tingkir Juga tidak lepas dari perguruan Taman Siswa Ki Hajar Dewantara. Pada zaman Taman Siswa Langen Carita menggunakan lagu dolanan anak-anak untuk pembelajaran dengan mengidolakan para pahlawan lokal sebagai sumber cerita tembang dolanan anak-anak. Tujuanya untuk memberikan sebuah pembelajaran kepada generasi muda pada waktu itu. Pembelajaran disini yang dimaksud adalah mengenai sebuah rasa cinta kepada kebudayaan lokal.

Seperti halnya pada Taman Tim penyusun mencoba memposisikan kedudukan nilai Edukasi dalam karya Drama Tari Langen Carita Jaka Tingkir dengan menggarap sebuah bentuk Drama tari yang menitikberatkan pada garap ceritanya dengan tujuan agar Para generasi muda saat ini lebih bisa mengenal dan menghargai cerita para pahlawan lokal seperti cerita Joko Tingkir (Pramutomo, 06 september 2017).

Dengan adanya sebuah bentuk teks cerita dan teks tembang dalam struktur Dramatik langen carita Jaka Tingkir dan dengan adanya inovasi dalam garap gerak, cerita, tembang dan narasi yang ada pada Drama Tari Langen Cerita Jaka Tingkir ini menginspirasi penulis untuk mengkaji lebih dalam lagi mengenai Makna teks dalam setruktur dramatik Drama Tari Cerita Langen Carita Jaka Tingkir. Teks sendiri mempunyai arti sebagai berikut. Menurut leech dalam buku "Pragmatik Genre Tari Pasihan Gaya Surakarta" yang ditulis oleh Maryono Teks adalah kontruksi dari hasil penggunakan sintaksis dan fonologi bahasa secara bermakna. Sejalan dengan pendapat tersebut, Teks adalah potongan dari bahasa tulis maupun lisan yang maknanya dapat dirunut dari prespektif strukturnya maupun fungsinya (Richards et al, 1992: 378).

Berdasarkan uraian latar belakang di atas, maka dapat dirumuskan pertanyaan sebagai berikut.:Bagaimana Bentuk Drama Tari Langen Carita Jaka Tingkir?, Bagaimana Makna Teks dalam Struktur Dramatik cerita Drama Tari Langen Carita Jaka Tingkir?

Seperti pada kebanyakan penelitian, studi ini juga tidak terlepas dari tinjauan pustaka. Tinjauan pustaka dalam penelitian ini dilakukan sebagai data tambahan dalam upaya untuk melihat objek material sekaligus untuk mengantisipasi adanya topik tulisan yang sama dengan penelitian ini. Referensi dalam tinjauan pustaka ini sedikit banyak terkait dengan obyek penelitian. Ada beberapa buku yang dijadikan sebagai referensi didalam penulisan ini diantaranya:. Buku yang ditulis oleh Sri Rochana $W$ dengan judul "langenDriyan Mangkunegaran Pembentukan dan Perkembangan Bentuk Penyajiannya". Buku ini berisi tentang munculnya Langendriyan sampai bentuk perkembangan penyajiannya. Manfaat yang diperoleh adalah mengetahui tentang asal usul Langendriyan. Buku yang ditulis oleh Ben Soeharto, N. Soepardjan dan Rejomulyo yang berjudul "Langen Mandrawanara Sebuah Opera Jawa". Berisi tentang Munculnya Langen mandrawanara dan sejarah dibaliknya. Manfaat yang diperoleh mengerti tentang sejarah langen Mandrawanara.

Dalam rangka mengkaji kehadiran Tari Langen Carito Joko Tingkir diperlukan beberapa teori yang terkait. Teori dan konsep yang digunakan untuk membedah masalah yang terjadi adalah teori pragmatik dan teori komposisi yang dapat dijelaskan seperti berikut: 
Menurut kamus besar Bahasa Indonesia pragmatik adalah berkenaan dengan syarat-syarat yang mengakibatkan serasi tidaknya pemakaian bahasa dan komunikasi. Selain itu juga mengambil pendapat dari Leech dalam buku yang berjudul Pragmatik Genre Tari Pasihan Gaya Surakarta ditulis oleh Maryono tahun 2010 yang berisi: "pragmatik mengkaji perilaku yang dimotivasi oleh tujuan-tujuan percakapan (1993: 45). Permasalahan tentang teks tembang dan teks gerak dalam struktur dramatik cerita Langen Carito Joko Tingkir dideskripsikan dengan menggunakan konsep Pragmatik.

Setelah menjelaskan tentang buku yang tinjauan pustaka berikut adalah teori yang digunakan dalam penelitian Langen Carita Jaka Tingkir. Penelitian ini menggunakan Teori pragmatik yang dikembangkan oleh Maryono dikatakan bahwa bentuk pertunjukan tari secara garis besar terdiri dari komponen dasar yang dapat dibedakan menjadi dua yaitu: komponen verbal dan nonverbal. Komponen yang bersifat verbal terdiri dari: (1) sastra tembang, (2) janturan atau monolog, (3) antawecana atau dialog, (4) geguritan atau puisi, dan (5) syair. Sedangkan komponen nonverbal terdiri dari: (1) tema, (2) alur cerita atau alur dramatik, (3) gerak, (4) penari, (5) pola lantai, (6) ekspresi wajah atau polatan, (7) busana, (8) musik, (9) panggung, (10) properti, (11) pencahayaan, dan, (12) setting (2012:24).

Kajian komponen verbal ini digunakan untuk mengungkap jenis-jenis Tindak tutur, fungsi tindak tutur, implikatur, realisasi prinsip kerja sama, realisasi setrategis kesantunan, dan jenis tindak tutur yang dominan pada masing-masing teks Drama Tari langen Carito Joko Tingkir. Adapun teori tindak tutur yang di kemukakan oleh
Kreidler meliputi assertive, performative, verdictive, eksspresive,directive, commissive dan phatic (1998, 183-194). Komponen tindak tutur digunakan untuk menganalisis komponen teks verbal sesuai dengan jenis tindak tuturnya.

Penelitian yang berjudul "Langen Carito Joko Tingkir"ini melalui pendekatan linguistik yaitu aspek kebahasaan memandang tari dalam bentuk bahasa. Peneliti menggunakan metode penelitian kualitatif menurut lexy J.Moleong, M.A dalam buku berjudul Metodologi Penelitian Kualitatif dijelaskan bahwa:

Peneliti kualitatif adalah penelitian yang bermaksud untuk memahami fenomena tentang apa yang dialami oleh subjek penelitian misalnya perilaku, persepsi, motivasi, tindakan, dll., secara holistik, dan dengan cara deskripsi dalam bentuk katakata dan bahasa, pada suatu konteks khusus yang dialamiah dan dengan memanfaatkan berbagai metode ilmiah (2012:06).

\section{KOMPONEN VERBAL DRAMA TARI LANGEN CARITA JAKA TINGKIR}

Bentuk adalah suatu objek fisik yang tampak oleh indra pengelihatan, tetapi bentuk fisik juga yang tampil sempurna mempunyai kekuatanberlanjut mampu menyinarkan "sesuatu" dalam suatu isi yang nonfisik atau makna (Tasman, 2008:49). Bentuyk dalam suatu tarian menjadi sebuah media ungkap yang digarap sedemikian rupa agar pesan yang ingin disampaikan oleh koreografer dapat tersampaikan kepada penonton atau penghayat. Ketiga komponen tersebut saling berkaitan dan menjadi sumber nilai pada setiap karya seni.

... Bentuk tari secara garis besar terdiri dari komponen-komponen dasar yang 
dapat dibedakan menjadi dua, yaitu komponen verbal dan non verbal. Komponen verbal dalam pertunjukan tari diantaranya terdiri dari: sastra tembang, monolog, dialog, puisi, dan syair...(Maryono, 2011:78).

Komponen verbal merupakan jenisjenis komponen atau unsur yang berbentuk kebahasaan. Merujuk pada fungsinya, tembang dolanan yang terdapat pada Drama Tari Langen Carito Joko Tingkir sebagai sarana informasi kepada penonton dan sebagai sarana penggambaran awal dalam sajian Drama tari Langen Carito Joko Tingkir. tembang Dolanan yang terdapat Pada Drama Tari Langen Carito Joko Tingkir sebagai sarana ekspresi dari penari dalam rangka ajak-ajak dan juga untuk menambah suasana gembira dan juga semangat kebersamaan.

Tindak tutur dikategorikan menjadi tujuh jenis meliputi: asertif jenis tindak tutur yang digunakan untuk memberikan informasi, performatif jenis tindak tutur yang digunakan untuk mengakibatkan keadaan tertentu, verdiktif jenis tindak tutur yang digunakan untuk menilai tindakan orang lain, ekspresif jenis tindak tutur yang digunakan untuk mengungkapkan ekspresi jiwa seseorang yang kaitannya denga psikologi seseorang,direktif jenis tindak tutur yang digunakan untuk menyuruh seseorang melakukan atau tidak melakukan suatu tindakan, komisif jenis tindak tutur yang digunakan untuk memberi komitmen atau janji, dan patik jenis tindak tutur yang digunakan untuk memberi sapaan kepada petutur tanpa memiliki maksud tertentu (kreidler, 1998: 183-194). Mengacu pada teori tindak tutur yang dinyatakan oleh Kreidler, maka komponen verbal yang terdapat dalam Drama Tari Langen Carito Joko Tingkir dianalisis sebagai berikut.

Tabel 1. Jenis-jenis tindak tutur teks tembang dolanan bagian kesatu.

\begin{tabular}{|l|l|l|}
\hline Penutur & $\begin{array}{l}\text { Jenis Teks Tembang } \\
\text { Dolanan }\end{array}$ & $\begin{array}{l}\text { Jenis Tindak } \\
\text { Tutur }\end{array}$ \\
\hline Narator & Yo kanca suka-suka & Ekspresif \\
\hline Narator & $\begin{array}{l}\text { Pada dolanan } \\
\text { tetembangan }\end{array}$ & Asertive \\
\hline Narator & $\begin{array}{l}\text { Ayo dolanan dasar, } \\
\text { lagi padang mbulan }\end{array}$ & Ekspresif \\
\hline Narator & $\begin{array}{l}\text { Langen carita, } \\
\text { dongengane jaman }\end{array}$ & Asertif \\
\hline Narator & $\begin{array}{l}\text { yo digatekno, muga } \\
\text { dadi tuladha }\end{array}$ & Directive \\
\hline
\end{tabular}

Konteks:

Peserta tutur: Penari (penutur) dan anak-anak sekolah SMKI surakarta beserta mahasiswa Institut Seni Indonesia surakarta (petutur). Tema: Ajakan . Tujuan: Mengajak para generasi muda untuk lebih mencintai kebudayaan lokal karena pada era globalilasasi sekarang ini para generasi muda tidak mengenal cerita tokoh sejarah disekitarnya, dengan adanya penggunaan tokoh Jaka Tingkir dengan karakter yang dimiliki yakni gagah, pemberani,bertanggung jawab diharapkan memberikan sebuah pelajaran kepada generasi muda untuk lebih membangun karakter yang bertanggung jawab. Tokoh Jaka tingkir diperankan oleh seorang anak Sekolah Menengah Pertama dari Sanggar Soeryasoemirat. Anak-anak perempuan dan laki-laki yang sedang menari dan juga gojekan menggambarkan sebuah kegembiraan anak-anak yang sedang bermmain drama dengan lakon atau Judul Jaka Tingkir. 
Tabel 2. Jenis-tindak Tutur pada Teks dialog bagian kesatu.

\begin{tabular}{|c|c|c|}
\hline Penutur/Petutur & $\begin{array}{l}\text { Jenis Teks } \\
\text { Dialog I }\end{array}$ & $\begin{array}{l}\text { Jenis Tindak } \\
\text { Tutur }\end{array}$ \\
\hline $\begin{array}{l}\text { Penari wanita I } \\
\text { penutur }\end{array}$ & Eh kanca kanca & Ekspresif \\
\hline $\begin{array}{l}\text { Semua penari } \\
\text { wanita petutur }\end{array}$ & wee.. ana apa & Ekspresif \\
\hline $\begin{array}{ll}\text { Penari laki-laki } \\
\text { penutur }\end{array}$ & $\begin{array}{l}\text { iki ana crita jaman pajang. Yaiku mula } \\
\text { bukane praja Mataram. Sing saiki } \\
\text { pecah dadi sekawan. } \\
\text { 1.Kasunanan } \\
\text { Mangkunegaran kang mapan } \\
\text { ana ing Surakarta Hadiningrat. } \\
\text { 2.Kasultanan lan Pakualam } \\
\text { kang mapan ana ing } \\
\text { Ngayogyakarta. }\end{array}$ & Asertif \\
\hline Penari Wanita II & $\begin{array}{l}\text { Oh dadi saka Pajang dadi Mataram } \\
\text { terus Amangkurat Agung dadi } \\
\text { Kartasura terus sakiki Surakarta } \\
\text { iku ta? }\end{array}$ & Asertif \\
\hline Penari Wanita 1 & $\begin{array}{l}\text { Iya bener. La iki ana salah siji } \\
\text { prajurit kang kena dadi tulada. } \\
\text { Arane yaiku mas Karebet utawa } \\
\text { Jaka Tingkir. Mula gandheng sakiki } \\
\text { wis pada siaga lan samapta, Karo } \\
\text { dapukane dewe-dewe. Becike sakiki } \\
\text { ayo nggelar langen carita kanthi } \\
\text { irah-iraha Jaka Tingkir Kridha } \\
\text { mugabisa dadi tepa tuladha. }\end{array}$ & Asertif \\
\hline
\end{tabular}

Konteks :

Peserta tutur: Penari wanita I sebagai penutur pada baris 1 dan 3 sebagai penutur. Selanjutnya semua penari bertindak sebagai penutur pada baris 2 dan Penari Wanita II bertindak sebagai penutur pada baris 4 . Kemudian penari laki-laki menjadi penutur baris 5. Tema: memberi informasi. Tujuan: memberikan informasi kepada teman-teman bahwa di daerah kita memiliki cerita rakyat tentang kerajaan pajang yang pecah menjadi empat bagian. dalam kisah kerajaan pajang tidak lepas dari tokoh Seorang Prajurit yang menjadi contoh budi pekerti luhur yaitu Mas Karebet atau Joko Tingkir. Joko Tingkir merupakan tokoh berwibawa, berani dan juga bertanggung jawab.
Tabel 3. jenis-jenis tindak tutur pada teks Tembang Nini bagian kesatu.

\begin{tabular}{|l|l|l|}
\hline Penutur/petutur & \multicolumn{1}{|c|}{$\begin{array}{c}\text { Jenis Teks } \\
\text { Tembang Nini }\end{array}$} & $\begin{array}{c}\text { Jenis Tindak } \\
\text { Tutur }\end{array}$ \\
\hline Semua penari & Yo kanca sawega & Ekspresive \\
\hline Semua penari & Nggelar langen carito & Asertive \\
\hline Semua penari & Kanthi suka lan gembira & Ekspresive \\
\hline Semua penari & Mugi dadi tuladha & Verdictive \\
\hline Semua penari & Tulada kang utama & Verdictive \\
\hline
\end{tabular}

Konteks:

Peserta tutur: semua penari putra dan putri sebagai penutur dari baris 1, 2, 3, 4, dan 5. Tema: Ajakan untuk membuat sebuah drama yang menceritakan tentang sejarah Jaka Tingkir. Tujuan untuk memperkenalkan pada generasi muda pada saat ini tentang sebuah Drama Tari yang menceritakan tentang sejarah Jaka Tingkir,agar para generasi muda lebih mencintai kebudayaan sendiri. Status sosial menggambarkan seorang anak-anakyang memiliki karakter riang, gembira juga polos yang sedang bermain bersama dengan teman-temannya menceritakan sebuah cerita pahlawan lokal yaitu Mas Karebet atau Jaka Tingkir dan berharap dengan adanya Drama Tari tersebut memberikan pembelajaran kepada generasi muda untuk lebih mencintai kebuayaan sendiri. situasi tutur: tidak formal

Tabel 4. Jenis-jenis tindak tutur pada teks Patalon a.

\begin{tabular}{|c|l|l|}
\hline Penutur/petutur & \multicolumn{1}{|c|}{$\begin{array}{c}\text { Jenis teks } \\
\text { Patalon A }\end{array}$} & $\begin{array}{c}\text { Jenis Tindak } \\
\text { Tutur }\end{array}$ \\
\hline Penari putra dan putri & $\begin{array}{l}\text { Babaring kidung } \\
\text { sanggit }\end{array}$ & Asertive \\
\hline
\end{tabular}




\begin{tabular}{|l|l|l|}
\hline Penari putra dan putri & Lelakoning urip & Asertive \\
\hline Penari putra dan putri & Langening carita & Asertive \\
\hline Penari putra dan putri & Babad tanah Jawa & Asertive \\
\hline
\end{tabular}

Terjemahan bebas

Peserta tutur: penari putra dan putri dari baris 1, 2, 3,dan 4.tema menceritakan sebuah sejarah cerita jaka tingkir. Tujuan memberi pelajaran tentang kebudayaan jawa melalui gerak, tembang dan tari. Status sosial seorang anak putra dan putri yang memiliki karakter riang, gembira juga polos sedang bermain dengan teman-temannya dan menceritakan sebuah sanggit atau cerita tentang Babad Tanah Jawa. Situasi tutur: tidak formal.

Tabel 5. Jenis-jenis tindak tutur pada patalon B bagian kesatu

\begin{tabular}{|l|l|l|}
\hline Penutur/petutur & Jenis teks patalon B & $\begin{array}{l}\text { Jenis tindak } \\
\text { Tutur }\end{array}$ \\
\hline $\begin{array}{l}\text { Penari putra dan } \\
\text { putri sebagai } \\
\text { penutur }\end{array}$ & Gatraning kanda ing demak bintara & Asertif \\
\hline $\begin{array}{l}\text { Penari putra dan } \\
\text { putri sebagai } \\
\text { penutur } \quad \text { Risang muda tumaruna karebet kang asma }\end{array}$ & Asertif \\
\hline $\begin{array}{l}\text { Penari putra dan } \\
\text { putri sebagai } \\
\text { penutur }\end{array}$ & Manggalayuda dadya tulada & Directif \\
\hline
\end{tabular}

Konteks:

Peserta tutur 10 penari anak putra dan putri dari baris awal sampai akhir sebagai penutur. Tema memberi informasi. Tujuan melanjutkan drama cerita Langen Carita Jaka Tingkir. Status sosial anak-anak sebagai pemberi informasi cerita yang memiliki karakter polos riang juga gembira sedang Melakukan Drama Tari dan mengangkat cerita tentang Mas Karebet. Mas Karebet atau Jaka Tingkir merupakan seorang pemuda yang berasal dari Pengging Trah Majapahit. Ceritera ini mengkisahkan perjalanan Jaka Tingkir yang penuh dengan rintangan seperti mengalahkan 40 ekor buaya, mengalahkan
Kebo Danu, dan akhirnya menjadi menantu Sultan Trengono Demak sampai pada menjadi Sultan Pajang.

Situasi tutur tidak formal.

Tabel 6. Jenis-jenis tindak tutur pada teks tembang perangan buaya bagian kedua

\begin{tabular}{|l|l|l|}
\hline $\begin{array}{l}\text { Penutur } \\
\text { /petutur }\end{array}$ & $\begin{array}{l}\text { Jenis teks tembang } \\
\text { Perangan }\end{array}$ & $\begin{array}{l}\text { Jenis tindak } \\
\text { Tutur }\end{array}$ \\
\hline Buaya 1 & h-duh raden kula nyuwun pangaksami & Performative \\
\hline Buaya 1 & Paringana gesang & Direktif \\
\hline Buaya 1 & Kula saguh dados abdi & Komissif \\
\hline Buaya 1 & Anyabrangaken paduka & Komissif \\
\hline
\end{tabular}

Konteks:

Penutur 1penari buaya dari baris 1-4 jaka tingkir bertindak sebagai petutur. Tema meminta maaf. Tujuan supaya di maafkan oleh Jaka Tingkir karena telah melawan Jaka Tingkir dan ingin memakannya dalam sebuah perjalanan. Status sosial buaya sebagai hewan yang sedang melawan jaka tingkir di sebuah sungai karakter yang dimiliki buaya rakus dan sangat buas namun ketika dalam peperangan dengan jaka Tingkir buaya kalah sehingga membuat 40 ekor buaya tersebut meminta ampunan agar Jaka Tingkir tidak membunuh 40 ekor buaya dalam sungai tersebut sehingga buaya tampak pasrah dan menyerahkan diri supaya jaka Tingkir memafkannya, dengan kekalahan tersebut buaya meminta agar Jaka Tingkir menerimanya menjadi abdi atau pengikut yang setia menjaga Jaka Tingkir dari sisi manapun. Situasi tutur formal

Tabel 7. Jenis-jenis tindak tutur pada teks tembang srepeg Megatruh bagian kedua

\begin{tabular}{|l|l|l|}
\hline Penutur /petutur & $\begin{array}{l}\text { Jenis teks tembang } \\
\text { Srepeg Megatruh }\end{array}$ & $\begin{array}{l}\text { Jenis tindak } \\
\text { tutur }\end{array}$ \\
\hline Sinden & Sigra milir sang getek sinangga bajul & Asertif \\
\hline Sinden & Kawan dasa kang jageni & Asertif \\
\hline Sinden & Ing ngarsa miwah ing pungku & Asertif \\
\hline Sinden & Tan apit ing kanan kering & Asertif \\
\hline Sinden & Sang gethek lampahnya alon & Asertif \\
\hline
\end{tabular}


Konteks:

Peserta tutur: pengisi vocal (sinden) sebagai peserta tutur dar baris 1, 2, 3, 4, dan 5. Tema : Jaka Tingkir menang melawan 40 ekor buaya. Tujuan: menjadi abdi dari Jaka Tingkir dan menjaga Jaka Tingkir dari sisi mana pun. Status sosial jaka tingkir sebagai satria yang mengalahkan 40 buaya, tokoh jaka tingkir memiliki karakter tenang, gagah dan berani. 40 ekor buaya sebagai lawan yang ingin mengalahkan jaka tingkir namun justru sebaliknya, tokoh buaya memiliki karakter buas dan juga rakus. Dengan adanya kekalahan buaya membuat para buaya ingin mengabdi kepada jaka tingkir sehingga membuat para buaya memohon ampun kepada Jaka Tingkir. Buaya kemudian siap menjaga Jaka Tingkir dari mara bahaya yang mengancam. Tempat berada di sungai dalam sebuah perjalanan jaka tingkir. Situasi tutur tidak formal

Tabel 8. Jenis-jenis tindak tutur pada teks tembang srepeg Megatruh bagian ketiga

\begin{tabular}{|l|l|l|}
\hline Penutur/petutur & $\begin{array}{l}\text { Jenis teks tembang } \\
\text { Demak }\end{array}$ & $\begin{array}{l}\text { Jenis tindak } \\
\text { tutur }\end{array}$ \\
\hline pengisi vocal & Sambunging kanda, ing demak bintara & Asertif \\
\hline pengisi vocal & Ana satriya jejuluk si dadung awuk & Asertif \\
\hline pengisi vocal & Pranyata sekti mandraguna lan digdaya & Asertif \\
\hline pengisi vocal & Sapa kang kuwawa bisa ngasorke & Asertif \\
\hline pengisi vocal & Krida lan tandange & Asertif \\
\hline pengisi vocal & Nenggih ta sang dadung awuk & Asertif \\
\hline pengisi vocal & Mulat mara sang satriya & Asertif \\
\hline
\end{tabular}

Konteks :

Peserta tutur seorang pengisi vocal sebagai penutur dari baris 1, 2, 3, 4, 5, 6, dan 7 yang menjadi penutur penari dan juga penonton. Tema: memberikan informasi tentang lanjutan cerita Jaka tingkir. Tujuan: mengerti tentang lanjutan cerita Langen Carita Jaka Tingkir.Situasi tutur:Non formal. Status sosial Dadung awuk yang dimaksud adalah prajurit demak bintara yang memiliki karakter berani
Tabel 9. Teks tembang palaran durma

\begin{tabular}{|l|l|l|}
\hline Penutur/petutur & $\begin{array}{l}\text { Jenis teks tembang } \\
\text { Palaran Durma }\end{array}$ & $\begin{array}{l}\text { Jenis tindak } \\
\text { tutur }\end{array}$ \\
\hline Jaka tingkir & Heh jejaka aja mati tanpa aran & Ekspresif \\
\hline Jaka Tingkir & Sapa sesilih reki & Asertif \\
\hline Jaka Tingkir & Maskarebet asma & Asertif \\
\hline Jaka Tingkir & Nedya dadya tamtama & Performative \\
\hline Jaka tingkir & Ja kemaki lengur bali & Verdiktif \\
\hline Jaka tingkir & Angono menda & Direktif \\
\hline Jaka tingkir & Timbang tumukung pati & Verdiktif \\
\hline
\end{tabular}

Konteks:

Peserta tutur Jaka Tingkir dari baris 1 , $2,3,4,5,6$, dan 7 . Tema memberi tahu. Tujuan supaya prajurit tidak menyombongkan diri dan lebih baik mundur dari pada nanti meninggal dunia. Status sosial jaka tingkir merupakan seorang pemuda daripengging Trah Mojopahit yang memiliki Karakter baik, gagah berani dna juga ksatria dalam sebuah perjalannya menuju pajang Jaka Tingkir menemui berbagai rintangan seperti melawan 40ekor buaya dan juga kebo danu Situasi tutur formal.

\section{BENTUK KOMPONEN NONVERBAL DRAMATARI LANGEN CARITO JOKO TINGKIR}

Komponen nonverbal adalah unsurunsur atau elemen-elemen yang bentuknya bersifat nonkebahasaan (Maryono, 2012:42). Bentuk dan wujud secara umum dapat berupa simbol, isyarat, kode, dan bunyibunyian, misalnya: tanda lalu lintas, morse, lambaian tangan, sirene, kentongan; lambang tersebut baru bermakna setelah diterjemahkan kedalam bahasa manusia (Lamuddin Finoza, 2005:2). Dalam pertunjukan Drama Tari Langen Carito Jaka Tingkir, komponen yang bersifat nonverbal merupakan elemen-elemen yang secara visual dapat dilihat, didengar, dinikmati, dan dihayati dengan indera manusia. Komponen 
nonverbal adalah komponen sebagian penyampai isi bentuk komponen yang bersifat nonverbal dalam pertunjukan tari diantaranya terdiri dari berbagai unsur: tema, gerak, penari, ekspresi wajah, rias, busana, iringan, panggung, properti dan pencahayaan (Maryono, 2011:78).

\section{Tema}

Berdasarkan tema yang digarap, komposisi tari dapat dibedakan antara yang diolah berdasarkan tema literer dan non literer, komposis tari literer komposis tari yang digarap dengan tujuan untuk menyampaikan pesan-pesan seperti: ceritera, pengalaman pribadi, interprestasi karya sastra, dongeng, legenda, cerita rakyat, sejarah, dsb( Sedyawati, 1986:22). Berdasarkan pendapat Sedyawati, Drama Tari langen Carita Jaka tingkir merupakan suatu bentuk drama tari yang bertemakan literer, mengingat tarian ini digarap dengan tujuan untuk menyampaikan cerita sejarah kepada generasi muda pada saat ini.

Tema pada Drama Tari Langen Carita Jaka Tingkir mengambil dari cerita sejarah Babad Jaka Tingkir. pengambilan cerita Jaka Tingkir dikarenakan adanya sebuah keprihatinan Pramutomo, Tubagus dan juga Slamet melihat kurangnya apresiasi generasi muda pada sebuah kesenian khususnya tari. Maka diambilah sebuah cerita sejarah yang berada disekitar surakarta. berikut cerita jaka tingkir mulai dari bedirinya demak Bintara hingga beralih ke pajang.

\section{Gerak}

Gerak adalah bahasa komunikasi yang luas, dan variasi dari berbagai kombonasi unsur-unsurnya terdiri dari beribu-ribu kata" gerak,juga dalam konteks tari gerak sebaiknya dimengerti sebagai bermakna dalam kedudukan yang lainnya (Suharto, 1985:16). Gerak sebagai bahasa komunikasi sepertinya halnya tim penyusun dalam penyusun gerak terdapat suatu maksud atau pesan tertentu yang ingin disampaikan kepada penonton

Bentuk gerak yang digunakan juga berbeda antara peran satu dengan lainnya. Peran Jaka tingkir menggunakan ragam gerak gagahan kambeng, dadhung awuk/ prajurit menggunakan ragam gerak bapang, penari anak putri menggunakan garak gerak kreasi, penari buaya juga menggunakan gerak kreasi. Bentuk sajian keseluruhan menggunakan gaya Yogyakarta hal ini dikarenakan tim penyusun memiliki basic gerak gaya Yogyakarta, namun para tim penyusun meggunakan para penari dari sanggar Suryasoemirat yang mempunyai kemampuan dasar gerak gaya Surakarta.

\section{Penari}

Penari adalah seorang seniman yang menyajikan keindahan gerak tubuhnya dengan melibatkan gaya tafir dari ide estetik pada sebuah koreografi maupun imajinasinya (Tasman, 2008:27). Penari dalam sajian tari Langen Carita Jaka Tingkir menyajikan nkeindahan gerak mereka sesuai dengan daya tafsir serta imajinasi dari masing-masing penari, daya tafsir serta imaji akan berpengaruh kepada peran yang dibawakan. Tari Langen Carita Jaka Tingkir disajikan oleh 5 penari perempuan dan 5 penari laki-laki. Keseluruhan penari dibagi menjadi 5 peran, yakni peran sebagai seorang anak perempuan, anak laki-laki, buaya, prajurit dan juga Jaka Tingkir. peran anak perempuan dibawakan oleh 5 anak 
perempuan, peran anak laki-laki diperankan oleh 5 anak laki-laki, peran buaya dibawakan oleh 5 anak prempuan, peran prajurit dibawakan oleh 4 anak laki-laki dan peran Jaka tingkir diperankan oleh 1 anak laki. Mereka memerankan 2 tokoh sekaligus. Peran penari anak perempuan di gambarkan sebagai seorang anak-anak yang sedang bermain dengan menggunakan baju warna warni

Alasan tim penyusun mengambil penari anak-anak untuk diperankan dalam sebuah Drama Tari langen Carita Jaka tingkir karena pada saat ini para generasi muda lebih memilih budaya barat dan juga cerita-cerita komik anak daripada cerita pahlawan lokal seperti Jaka Tingkir. kurangnya apresiasi generasi muda tersebut membuat Tubagus, Slamet dan juga Pramutomo memilih penari yang masih berada di tingkat SMP supaya para generasi muda pada saat ini lebih mencintai kebudayaan sendiri.

\section{Ekspresi Wajah}

Ekspresi wajah atau polatan merupakan perubahan kondisi visual rayt muka atau wajah seseorang (Maryono, 2012:60). Ekspresi wajah atau polatan penari dalam sajian Drama Tari Langen Carita Jaka Tingkir diperlihatkan dengan melalui mimik wajah yang dapat dilihat secara jelas dalam setiap adegannya. Ekspresi wajah pada babak pertama yang di perankan oleh 10 penari putra dan putri yaitu mencerimankan kegembiraan,senang, dan juga riang. Kegembiraan tersebut karena menggambarkan sebuah ajakan seorang anak kepada temannya untuk bermain drama Cerita Jaka Tingkir. ekspresi wajah pada babak kedua ini menunjukan bentuk wajah garang dan gagah hal ini mencerminkan 40 ekor buaya yang kuat, dan menyeramkan. Pada babak ketiga ekpresi yang diperankan para penari sebagai prajurit terlihat sangat gagah, berani dan juga penuh dengan amarah. Dan pada babak empat ekpresi yang diperankan oleh Jaka Tingkir sangat Antep menggambarkan seorang satria yang gagah dan berani melawan 40 ekor buaya dan kebo danu.

\section{Kostum}

Bentuk atau mode busana dalam pertunjukan tari dapat mengarahkan penonton pada pemahaman beragam jenis peran atau figur tokoh (Maryono, 2012:61). Pemakaian bentuk atau model busana dalam pertunjukan Drama Tari langen Carita Jaka Tingkir dibedakan sesuai dengan peran yang dibawakan.

Kostum yang digunakan pada penari putri menggunakan kostum kebaya polos dengan rok lurik memiliki warna senada dengan kebayanya. Kebaya menggunakan 5 jenis warna yang berbeda disetiap penarinya. Warna yang dipilih cenderung terang menggambarkan keceriaan anakanak yang sedang bermain. Warna terang cenderung disukai oleh anak-anak maka dari itu warna terang seperti merah, hijau, kuning, biru dan pink dipilih untuk menyesesuaikan peran anak-anak. Penggunakan kebaya dan rok lurik dimakudkan agar lebih mudah untuk berganti kostum pada perpindahan babak 1 ke babak 2 .

\section{a. Kostum penari buaya \\ Para penari buaya menggunakan} kostum berwarna hijau, kepala buaya warna hijau, kemben warna hijau dan juga celana warna hijau dan motif lengkung tumpuk berwana kuning keemasan dan sampur 
warna kuning. Kostum yang dikenakan memiliki motif seperti sisik hal ini menggambarkan seekor buaya yang memiliki kulit bersisik. Dengan adanya kostum tersebut diharapkan lebih menunjang karakter yang di perankan.

1. Kepala buaya

Kepala yang digunakan berwarna hijau dengan mata berwarna putih, rambut ikal di begian belakang, warna kuning pada bagian depan, gigi runcing pada bagian samping serta hiasan merah pada bagian telinga. Penggunaan warna hijau dimaksudkan agar lebih mengambarkan seokor buaya yang berada didanau, warna putih pada bagian matadimaksudkan agar lebih menonjol dan memberi kesan menyeramkan. Rambut digunakan untuk menutupi bagian belakang bentuk kepala tersebut. Kemudian kemudian warna kuning pada bagain depan digunakan untuk menggambarkan bentuk kepala buaya agar lebih terlihat nyata.

2. Kace pada kostum buaya

kace merupakan kelengkapan kostum yang dikenakan untuk menutupi bagian dada.kace berwarna dasar hijau dan hiasan berwarna kuning emas pada bagian pinggir kace. Fungsi pemakaian kace ini adalah menutupi bagian dada sekaligus sebagai aksesoris agar kostum tampak lebih menarik. Warna merah pada kace dipilih untuk mewujudkan kesan berani dan menyerasikan dengan bentuk kostum yang lain agar lebih serasi.

3. Mekak

Kostum atasan yang digunakan penari buaya yaitu mekak dengan bahan bludru berwarna hijau dan memiliki motif lengkung kuning dan merah. Motif lengkung dimaksudkan sebagai kulit buaya yang memiliki bentuk kulit seperti sisik kemudian warna kuning yang digunakan supaya bentuk sisik lebih terlihat jelas.

4. Rampek.

rampek merupakan bagian dari kostum buaya yang terbuat dari kain bludru, pada bagian depan terdapat motif seperti lengkung yang menyerupai sisik berwarna kuning. Pada bagian samping diberi manik-manik supaya lebih terlihat menarik. Kegunaan rampek untuk kain penutup bagian bawah setelah menggunakan jarik.

5. Celana

Celana yang digunakan untuk kostum buaya menggunakan celana pendek dengan panjang dibawah lutut dan berwarna hijau. Celana ini dilengkapi dengan hiasan lengkung-lengkung berwarna emas. Pemakaian celana dengan panjang dibawah lutut dan sedikit longgar hal ini dikarenakan agar para penari lebih leluasa untuk bergerak. Warna hijau dipilih karena menyesuaikan warna baju atasan yang dikenakan. Warna emas yang digunakan paca celana dengan corak lengkung menumpuk diperuntukan untuk memberi kesan kulit buaya.

Stagen digunakan untuk mengikat dan mengencangkan jarik. Pemakaian stagen juga bertujuan agar penampilan lebih tampak rapi. Selain itu kegunaan stagen untuk membuat bagian pinggang dan perut tampak lebih rata dan juga rapi. Warna stagen yang digunakan bebas karena penggunakan stagen sendiri tertutup oleh celana dan jarik. 
1. Kostum Jaka Tingkir dan dadhung awuk

Kostum yang digunakan penari Jaka Tingkir menggunakan bentuk kostum gaya Yogyakarta hal ini terlihat pada pemakaianjarik nyupit urang. Kostum yang dikenakan menggunakan iket, sampur gendala giri, celana bludru merah, jarik, epek timang.

a. Iket

Iket merupakan kelengkapan kostum yang dikenakan dengan cara di ikatkan dikepala . iket dengan warna merah dnegan corak batik berwarna kuning digunakan sebagai kelemgkapan kostum pada penari prajurit dan juga Jaka Tingkir. bagi masyarakat jawa Iket iket merupakan kelengkapan penutup kepala bagi masyarakat pedesaan yang sudah berkeluarga yang kebanyakan para orang tua lakilaki. Pemakaian iket pada penari Jaka Tingkir menjadi tepat baik pemakaian sebagai Jaka Tingkir atau pun sebagai masyarakat desa. Mengingat tokoh tersebut merupakan figur dari masyarakat pedesaan.

b. Celana bludru

Celana yang digunakan pada kostum Jaka Tingkir dalam pertunjukan Drama Tari langen Carita Jaka Tingkir menggunakan celana bludru pendek berwarna merah. Warna merah yang digunakan melambangkan keberanian soorang jaka Tingkir. c. Udeng gilik

Udeng gilik digunakan pada kepala penggunaan guling dimaksudkan untuk membedakan peran antara dadung awuk dan juga jaka tingkir. Warna guling digunakan pada dadung awuk berwarna hitam dengan hiasan emas terlilit pada guling.

6. Iringan

Iringan dalam sajian Drama Tari Langen Carita Jaka Tingkir didominasi oleh beberapa ragam ricikan gamelan. Sebagaimana alat musik pada umunya, gamelan adalah hasil olah budi manusia untuk mengungkapkan rasa estetika atau rasa mencurakan keindahan. (Santoso, tanpa tahun:1). Sesuai dengan pendapat santoso, iringan gamelan dala sajian Drama Tari Langen Carita Jaka Tingkir adalah sebagai media untuk mengungkap estetika atau rasa keindahan dari dalam diri komposer yang kemudian dicurahkan kedalam iringan sajian tari. Selain untuk mengungkap estetika, iringan gamelan juga digunakan untuk menambah serta mendukung suasana dalam setiap bagian cerita Drama Tari Langen Carita Jaka Tingkir. Dalam perannya musik memiliki peran dan fungsi yang sangat penting yakni, memberi tekanan dan kekuatan pada bagian gerak-gerak tertentu sehingga gerakan tampak lebih rampak. Iringan yang igunakan menggunakan lancaran 3/4, ladrang, ketawang bajul, sampak, ladrang dan srepeg megatruh.

7. Panggung

Panggung merupakan tempat 
diadaknnya pertunjukan, tempat pertunjukan Drama TariLangen Carita Jaka Tingkir berbentuk Pendapa yang berada di SMKI Surakarta.

8. Pola lantai

Pola lantai atau gawang dalam sajian tari merupakan salah satu unsur yang memberikan kontribusi penting dalam aktualisasi visual (Maryono, 2012:58). Aktualisasi visual tersebut tampak dari beberapa pola lantai yang ditunjukan untuk menunjukan identitas peran penari, seperti bentuk bola lantai berbaris lurus menunjukan identitas sebagai seorang prajurit. Bentuk-bentuk pola lantai yang sering digunakan dalam sajian Drama Tari Langen Carita Jaka Tingkir adalah bentuk pola lantai barisan, bentuk pola lantai bergerombol 4 dan juga jejer 2. Bentuk pola lantai yang dipilih menyesuaikan tokoh cerita dalam kehidupan nyata. Berikut pola lantai Drama Tari Langen Carita Jaka Tingkir.

\section{PENUTUP}

Drama Tari langen Carita Jaka Tingkir merupakan sebuah bentuk garapan Tari yang menitik beratkan pada sebuah tembang dan cerita yang kemudian di tarikan dalam sebuah bentuk sajian gerak dalam drama, dengan adanya perhatian oleh Slamet, R M Pramutomo dan Tubagus mulyadi mengenai kurangnya apresiasi generasi muda terhadap tari. Penggarapan Drama Tari Langen Carita Jaka Tingkir diharapkan mampu memberikan sebuah pelajaran kepada para generasi muda saat ini untuk lebih mencintai kebudaan sendiri terutama tentang sebuah cerita pahlawan local yang ada disekitar. Drama tari langen carita jaka tingkir digarap dengan menggunakan tembang dolanan anak.

\section{DAFTAR PUSTAKA}

Ayuningtyas, Abdiah.

2010. Skripsi "Fungsi Teks Kesenian Pitutur Madya Gatholoco Dalam kehidupan Masyarakat Ngrantun Magelang". Institus seni Indonesia Surakarta.

Fitriani, Ria.

2016 Skripsi." Pragmatik Tari Kiongkong

Dusun Plawan Ngargoyoso

Karanganyar. Institut Seni Indonesia Surakarta.

Hadi,Y. Sumandyo.

2003 Aspek-aspek dasar koreografi kelompok. Yogyakarta: yayasan Untuk Indonesia.

Haryadi, Puri.

2014 "fungsi Teks Kesenian Pitutur Madya

Gatholoco Dalam Kehidupan

Masyarakat Ngrantun Magelang".

Institut Seni Indonesia Surakarta.

Haryono, Sutarno.

2010 Kajian Pragmatik Seni Pertunjukan Opera Jawa. Solo: ISI Press.

Soedarsono, Djoko Soekiman, Retna Astuti. 1984/1985 Gamelan, Drama Tari, Dan Komedi Jawa. Surakarta: Proyek Penelitian Dan Pengkajian Kebudayaan Nusantara (Javanologi) Departemen Pendidikan Dan Kebudayaan .

Soeharto, Ben, N Soepardjan, Rejomulyo.

1999 "Langen Mandrawanara Sebuah Opera Jawa". Yogyakarta: Yayasan Untuk Indonesia.

Sri, Rochana W .

2006 Langendriyan Mangkunegaran Pembentukan dan Perkembangan Bentuk Sajiannya. Surakarta: ISI Press. Sutarno Haryono.

2014 Jurnal Greget" Sastra Tembang Pada Kontekstual Adegan Damar Wulan Sebagai Penguasa Majapahit dalam Tari Lengendriyan". 
Suwandi, Raden Mas.

1979 Serat Langen Driyan Pustakaweni, Alih Aksara Woro Ariandini.

Departemen P dan K: Proyek Penerbitan Buku Sastra Indonesia dan Daerah.

Tim Departemen Pendidikan dan Kebudayaan.

1981 BabadJakaTingkir:BabadPajang.Jakarta: Departemen Pendidikan dan Kebudayaan.

\section{NARASUMBER}

Ardi Gunawan (28 Tahun) composer dalam pembuatan karya Drama Tari Langen Carita Jaka Tingkir. Gebang rt 02/02 Kamal Mbulu Sukoharrjo.

Bimo (14 tahun) penari putra dan sebagai dadhung awuk, Sanggar Soeryasumirat.

Cinta (12 tahun) penari anak putri dan penari buaya, Sanggar Soeryasumirat.
Deren (12 tahun) penari anak putri dan penari buaya, Sanggar Soeryasumirat.

Gatot (35 tahun) pelatih penari putra, Sanggar Soeryasumirat.

Pramutomo. RM. (49 tahun) dosen institut seni Indonesia surakarta Sekaligus sutradara dalam pembuatan karya Langen carito Joko Tingkir Kadipaten Kidul No. 44 Yogyakarta.

Slamet (51 tahun) dosen Institut seni Indonesia surakarta sekaligus sebagai sutradara Tari langen carito Joko Tingkir Ngoro Tengah RT.03/RW4. Triyagan Mojolaban Sukoharjo.

Sutrisno (35 tahun) asisten sutradara dan pelatih penari putra, sanggar Soeryasumirat.

Tias (33 tahun) sebagai asisten sutradara dan pelatih penari putri dan buaya. Sanggar Soeryasumirat. 